\title{
The role of demographic and motivational factors on mobile commerce usage activities in South Africa
}

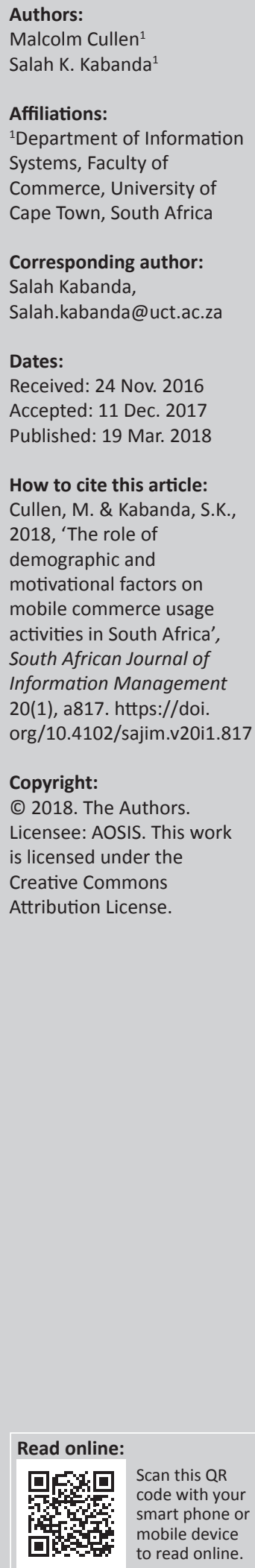

Background: Many studies have examined the mobile commerce phenomenon and most of these have focused on understanding the organisational and environmental factors that affect its adoption. Few have examined how an individual's characteristics and their perceived motivational appetite affect their mobile commerce usage and specifically the activities they engage in.

Objectives: This study examines the role of demographics (individuals' characteristics) and motivational factors on mobile commerce usage activities from the South African perspective.

Method: An objective approach and a positivistic stance were followed. The research model and instrument from earlier studies by Chong (2013a) were contextualised to suit this study. Data collection was done through an online questionnaire, 88 responses were received and 81 used for data analysis.

Results: The findings show that age is significantly related to mobile commerce transactions, and one's education status influences the following mobile commerce usage activities: transactions and location-based services. One's gender influences how one uses mobile commerce. A significant relationship between all three motivational variables and mobile commerce usage activities is evident.

Conclusion: The findings provide the financial services industry and providers of mobile commerce offerings with a better understanding of the relationships between customer demographics and the mobile commerce activities they engage in. An additional variable of customer income has been identified for future studies to better understand the relationship.

\section{Introduction}

Mobile commerce (m-commerce) refers to any transaction conducted on a wireless handheld device (Chong 2013b) and is postulated to have a significant influence on business and society (Bhatti 2015). For example, organisations can benefit from increased revenues and profit (Wu \& Wang 2005) whilst end users benefit in terms of 'ubiquity, convenience, localization and personalization [sic]' (Phuangthong \& Malisawan 2005:1). Mobile commerce users engage in various activities such as content delivery, commercial transactions, location-based services, emergency purposes and entertainment (Chong 2013a; Ngai \& Gunasekaran 2007).

Mobile commerce has provided several benefits to most organisations in developing countries. For example, in South Africa, the translation industry states that they have:

become mobile professionals, that is, they are not confined by traditional geographical and locational boundaries, but can interact with clients at any time and thus are able to create workspaces anywhere. (Selyer \& Mugova 2017:1)

Donner, Marsden and Gitau (2011) identified utility, entertainment and connection as the various $\mathrm{m}$-commerce usage activities in South Africa. Mobile commerce in South Africa and other developing countries could potentially transform these economies because of the contextual characteristics these economies present (Joubert \& Van Belle 2013), namely a demographic of low personal computer (PC) and broadband access, a high and growing smartphone penetration percentage, steady advancements made in mobile technology and services and the increase in number of individuals who only access the Internet and its many related services such as instant messaging, and m-commerce, on a mobile device (Kakihara 2014; Kreutzer 2009). This is significant as m-commerce offers many benefits, both for the organisation providing $\mathrm{m}$-commerce service and for end users consuming it. However, for organisations to capitalise on these benefits, they need to understand their customers' needs and be informed of what factors influence an individual towards a particular m-commerce usage activity. 
Many studies have focused on organisational and environmental factors that affect m-commerce adoption, but few have examined how an individual's characteristics and their perceived motivational appetite affect their m-commerce usage and specifically the activities they engage in. This paper is based on Chong's (2013a) study, which examined the relationships between demographic and motivational variables with $\mathrm{m}$-commerce usage activities. The purpose of this study is to contextualise Chong's work to South Africa and provide a better explanation of how demographic and motivational factors influence $\mathrm{m}$-commerce usage in South Africa. In so doing, the study seeks to contribute towards a better explanation of how demographic and motivational factors influence $\mathrm{m}$-commerce usage in South Africa. The findings would provide the financial services industry and providers of $\mathrm{m}$-commerce offerings with a better understanding of the relationships between customer demographics and the $\mathrm{m}$-commerce activities they engage in, to improve and customise their product offerings.

The rest of the paper is structured as follows: The 'Conceptual Background' section will provide a literature review on m-commerce, specifically in a developing country context. This is followed by the 'Methodology' section, which discusses the research approach, paying attention to how the data were collected and analysed. Then, the field research findings are documented in the 'Findings' section. An extrapolation of the field research findings in the context of the literature is made in the 'Discussion' section. The conclusion concludes and provides recommendations and future research work related to this study.

\section{Conceptual background $\mathrm{M}$-commerce in developing countries}

Developing countries are typically characterised by a high cost of Internet access and low PC and broadband access when compared to developed countries (Chetty et al. 2013; Kakihara 2014). The study by Touray, Salminen and Marsu (2013) on Information Communication and Technology (ICT) barriers and critical success factors in developing countries calls out (among others) technical constraints such as poor network reception and slow Internet connection, education and skills, which indicate poor literacy skills and lack of ICT skills; economic issues such as low per capita income; and socio-cultural issues such as language barriers. Overcoming widespread poverty is still a major challenge, specifically in most African countries (Wentzel, Diatha \& Yadavalli 2013).

The penetration of mobile phones in developing countries has dramatically changed business and individual communications and is thought to have a positive effect on the interaction. According to Budree and Williams (2013), mobile phone penetration is high in developing countries, even in rural settings where people might be deprived of basic services such as water and electricity. This has resulted in many studies that have attempted to understand the

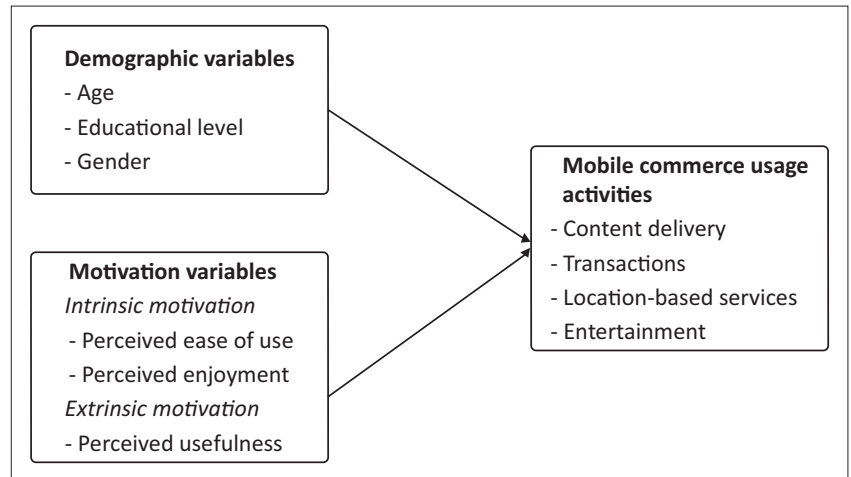

Source: Chong, A.Y.L., 2013a, 'Mobile commerce usage activities: The roles of demographic and motivation variables', Technological Forecasting and Social Change 80(7), 1350-1359. https://doi.org/10.1016/j.techfore.2012.12.011

FIGURE 1: Research model.

phenomenon in the developing context, such as Donner et al. (2011), who identified the various m-commerce usage activities in South Africa. Their findings show that utility, entertainment and connection were the main m-commerce usage activities. Chong (2013a) identified content delivery, transaction, location-based services, emergency purposes and entertainment as the main m-commerce usage activities in China. Similar findings were reported by Pagani (2004) and Ngai and Gunasekaran (2007).

In the existent literature of $\mathrm{m}$-commerce there has been limited focus on the role of demographics and motivational factors on adoption in the developing countries, specifically in Africa. This study, therefore, uses the model by Chong (2013a) to examine the role of demographics and motivational factors on adoption in South Africa. According to Chong, as shown in Figure 1, motivation and demographic variables are positively related to the usage of $\mathrm{m}$-commerce activities (e.g. content delivery, transactions, location-based services and entertainment).

\section{Demographic factors}

The most examined demographic indicators are gender, age and education. Past studies have confirmed that there is a strong and negative correlation between age and mobile Internet use (Chong 2013a). For example, in Taiwan and the United States, mobile Internet usage is more prominent in young males, with Taiwan showing strong usage in young males between the ages of 21 and 40 years old, and the United States with males between the ages of 18 and 35 (Okazaki 2006). There is a similar trend in Kenya, where m-commerce use is more pronounced among the younger generation (Hayden \& Webster 2014).

In the South African context, 'adolescents and the youth are the first adopters of mobile technology, with $72 \%$ of $15-$ to 24-year olds having a cell phone' (Beger, Sinha \& Pawelczyk 2012:3), the majority of them, who are students, owning a mobile phone 'in the category of smartphones, bearing modern features that facilitate instant messaging, exchange of data and information as well as speedy access to information via the Internet' (Shava, Chinyamurindi \& 
Somdyala 2016). As such, students reported the intensive use of mobile phones to access mobile Internet applications (because it is considerably more accessible), at a far greater level than they report using desktop computers to access the Web (Kreutzer 2009).

Chong (2013a) reports that age negatively affects m-commerce activities, specifically in terms of content delivery, transactions and entertainment. This is partly because of the fact that the elderly are usually forgotten during product design, development and marketing, and thus their needs are not catered for in the final consumption of the product (Mallenius, Rossi \& Tuunainen 2007); or the fact that there is a negative relationship between age and Internet self-efficacy (Chung et al. 2010). For example, as per the South African mobile consumer report (Mobility 2011), 'usage of mobile banking peaks in the $26-34$ age group, at $41 \%$, and drops to $11 \%$ in the over-45 group', suggesting that age is a factor in m-commerce usage. Not all of these findings are supported fully in the literature, however; specifically, Hew et al. (2016) found that age did not have any moderating effects on mobile entertainment services, emphasising that other factors such as quality of service play a bigger role when explaining usage. For the purposes of this study, it is hypothesised, as in Chong (2013a), that:

H1: age is negatively related to m-commerce usage in terms of content delivery, transactions, location-based services and entertainment.

Studies such as those by Teo (2001) and Chong (2013a) have confirmed that education positively affects m-commerce usage, particularly in transaction-based activities and locationbased services. Chong's (2013a) study also highlighted that education plays no significant role in content delivery such as messaging and downloading, or entertainment purposes such as listening to music. Teo (2001), however, found that education has a positive influence on general Internet usage and it is therefore hypothesised, as in Chong (2013a), that:

H2: educational level is positively related to the usage of $\mathrm{m}$-commerce in terms of the following activities: content delivery, transactions, location-based services and entertainment.

Finally, a number of previous studies have examined the role that gender plays in Internet usage and online shopping behaviour (Hasan 2010; Hwang 2010; Okazaki 2006). Findings from these studies are inconsistent, with some results showing males as being more dominant in mobile Internet adoption, with a wide population using it for both personal and work-related activities, whilst others did not show any significant difference between males' and females' mobile Internet usage (Okazaki 2006). Hasan (2010) argues that the biggest difference between females and males is in their cognitive attitude, explaining that males prefer the utility of online shopping more so than females. Tecnológica et al. (2015) suggest that females prefer interpersonal communication rather than a technology-based medium. Stork, Calandro and Gillwald's (2013) study on mobile
Internet use in Africa concluded that mobile Internet usage is fairly even between genders in Namibia and Tanzania but is biased towards males in Uganda, Ethiopia and Rwanda because females in these three countries were less educated and had lower disposable income than their male counterparts. Donner et al. (2011) highlighted gender differences in ICT usage in South Africa and found that although women had access to Internet-enabled smartphones, they relied on a male counterpart such as a brother, husband or son to make use of mobile Internet services, citing a lack of awareness of the capabilities of their devices, or finding the tasks too complicated to perform. Whilst Donner et al.'s (2011) research was aimed at a particular demographic of women, specifically those in an informal settlement, other studies have also made reference to the significance that gender has on mobile usage patterns, such as North, Johnston and Ophoff's (2014) study on South African university female students, who were found to use their mobile phones more for safety and socialising than their male counterparts. The South African mobile consumer report (Mobility 2011) also confirms that male usage of mobile banking services far outpaces that of females, at $56 \%$ versus $44 \%$. Gender does, therefore, have an influence on Internet use and we, therefore, hypothesise, as in Chong (2013a), that:

H3: males are more likely to use m-commerce for the following activities: content delivery, transactions, location-based services and entertainment.

\section{The role of motivational variables}

The motivational model by Davis, Bagozzi and Warshaw (1992) posits that Internet users' behaviours differ depending on whether their motivation is extrinsic or intrinsic. Most studies have claimed that intrinsic motivation is an important driver of employee attitudes and, in most cases, is substantively associated with both employee satisfaction and turnover intention (Cho \& Perry 2012). Padilla-Meléndez, Del Aguila-Obra and Garrido-Moreno (2013:307) see intrinsic motivation as the performance of an activity for no apparent reason other than the process of performing it. Such intrinsic motivational behaviour is evoked from the feeling of pleasure, joy and fun - commonly characterised as one's perceived enjoyment of the activity (Lee, Cheung \& Chen 2005:1099). Perceived enjoyment is thus a key intrinsic motivator for technology adoption and usage, and it 'represents the perceived enjoyment linked with the use of a particular technology in itself, rather than the potential performance outcome of using such a technology' (Ayeh, Au \& Law 2013:134).

Ramayah and Ignatius (2005) indicate that perceived ease of use and perceived enjoyment were positively related to intention to shop online in the Malaysian context. Furthermore, perceived ease of use $(\beta=0.78, p<0.01)$ was found to be a significant predictor of perceived usefulness.

In South Africa, Dlodlo and Mafini (2013:6) found perceived enjoyment to be statistically significant and correlated 
positively with frequency of m-commerce usage among consumers. The authors concluded that:

the higher the levels of fun and excitement that are derived by Generation $\mathrm{Y}$ consumers from utilising $\mathrm{m}$-commerce technologies, then the higher the frequency of use will be of that mobile platform for commercial transactional purposes. (p. 6)

On this basis, we hypothesise, as in Chong (2013a), that:

H4: perceived enjoyment is positively related to m-commerce usage.

Padilla-Meléndez et al. (2013:307) define extrinsic motivation as the performance of an activity for achieving valued outcomes that are distinct from the activity itself, such as improving job performance, pay, etc. According to Dysvik and Kuvaas (2013:2), 'employees who are extrinsically motivated work harder to attain a desired consequence or to avoid a threatened punishment'. Such employees tend to be driven by their perceived values, which explains the utility values for system usage, benefits derived and perceived ease of use, which is a predictor for an individual's intention to adopt and use a system. Previous studies have shown that perceived ease of use has a positive correlation with behavioural intention, both in a direct effect as well as an indirect effect through perceived usefulness or benefits (Bhatti 2015). For example, Erasmus, Rothmann and van Eeden (2015) examined technology acceptance within a South African user environment and their findings show:

a significant path from perceived usefulness of the information system to attitudes towards and behavioural intentions to use it. Furthermore, behavioural intention to use the system predicted actual use thereof. (p. 1)

They concluded that perceived ease of use indirectly affected attitudes towards and behavioural intentions to use via perceived usefulness of the information system. Whilst examining retail banking customers' attitudes towards Internet banking services in South Africa, Maduku (2013) found perceived usefulness and perceived ease of use were some of the factors that explained attitude and consequently use. On this note, we hypothesise, as in Chong (2013a), that:

H5: perceived ease of use is positively related to m-commerce.

H6: perceived usefulness is positively related to m-commerce in terms of the following activities: content delivery, transactions, location-based services and entertainment.

\section{Methodology}

The study followed an objective approach and was positivistic in nature. The implication here is that we do not seek to give explicit recognition to the world of consciousness and humanly created meanings (Ngwenyama \& Lee 1997) and acknowledge that the data that is gathered will be value-free data (Walsham 1995:376). Research participants in the study were the general public who had previously or were currently engaged in m-commerce activities. This was one of the requirements to participate in the study. Attention for the survey was garnered through sharing it online on social networks, namely LinkedIn, Facebook and Twitter, from the researcher's personal profile as well as through an email campaign and the distribution of physical copies. The database used for the email campaign was the researcher's address book. Physical copies were distributed in Wynberg, Cape Town, from two large public transport hubs and a large shopping centre in its vicinity because of its high footfall location. Having access to online resources allowed the survey to reach those members of the public who were not physically located in the Western Cape region of South Africa, which is where the researcher was based. Then, self-selection sampling was used to allow the public respondents to choose to take part in the study of their own accord.

Data collection was done through a survey questionnaire. The research instrument was developed using the constructs identified in Figure 1 as presented in Table 1. The instrument has been tested in prior research by Chong (2013a). The research instrument was structured as follows: Section 1 of the questionnaire captured the kinds of m-commerce activities that the respondents engage in; Section 2 captured the influence of motivational variables on $\mathrm{m}$-commerce usage and Section 3 captured demographic variables. Section 1: M-commerce Usage Activities and Section 2: Motivational Influences captured numerical data against a five-point Likert scale. The research instrument was piloted on several individuals familiar with $\mathrm{m}$-commerce to gather their feedback. The intention of the pilot test was to ascertain that the questionnaire was clear and that it was not taking too long to complete. Feedback received was consistent across the group, confirming that the survey could easily be completed in under $10 \mathrm{~min}$, but more importantly that the questions themselves were not easy to understand and left a lot to interpretation. Thus, a number of questions were rewritten with the focus on plain English descriptions to eliminate respondents' understanding the questions in different ways. Then, the process of data collection commenced. Completed survey questionnaires were submitted online anonymously on surveymonkey.com from members of the public.

Each response was allocated a unique reference number allowing for easy data preparation and analysis

TABLE 1: Research instrument design.

\begin{tabular}{llcc}
\hline Section & Constructs & Question & Related hypothesis \\
\hline 1 & Content delivery & Q1 & $\mathrm{H} 1-\mathrm{H} 6$ \\
& $\begin{array}{l}\text { Transactions } \\
\text { Location-based } \\
\text { services }\end{array}$ & $\mathrm{Q} 2$ & $\mathrm{H} 1-\mathrm{H} 6$ \\
& Entertainment & $\mathrm{Q} 3$ & $\mathrm{H} 1-\mathrm{H} 6$ \\
& Perceived ease of & $\mathrm{Q} 5$ & $\mathrm{H} 1-\mathrm{H} 6$ \\
& use & & $\mathrm{H} 5$ \\
& Perceived usefulness & $\mathrm{Q} 6$ & $\mathrm{H} 6$ \\
& Perceived enjoyment & $\mathrm{Q} 7$ & $\mathrm{H} 4$ \\
& Gender & $\mathrm{Q} 8$ & $\mathrm{H} 3$ \\
& Age & $\mathrm{Q} 9$ & $\mathrm{H} 1$ \\
& Education & $\mathrm{Q} 10$ & $\mathrm{H} 2$ \\
\hline
\end{tabular}

Source: Chong, A.Y.L., 2013a, 'Mobile commerce usage activities: The roles of demographic and motivation variables', Technological Forecasting and Social Change 80(7), 1350-1359. https://doi.org/10.1016/j.techfore.2012.12.011 
in statistics tools. In total, 88 responses to the questionnaire were received. Seven of the responses were only partially completed, leaving 81 for data analysis. The average time to complete the survey was $10.3 \mathrm{~min}$; however, there were a few outliers taking some $30-40 \mathrm{~min}$, with the most extreme taking nearly $3.5 \mathrm{~h}$. Removing the few outliers brought down the average time to complete the survey to $5.5 \mathrm{~min}$. Social media proved to be the most successful channel for gathering responses. The Facebook post used to gather most of the data was liked three times and shared seven times by respondents throughout South Africa. Similarly, the LinkedIn post and Twitter posts received two and one likes, respectively. The combined social media reach attracted a total of 46 responses. The email campaign brought in 30 responses. No one completed a physical paper questionnaire, but 12 responses were generated from distributing a web link with the physical paper, indicating that people prefer to complete surveys online at a time that suits them.

Initial data processing and exploration was done in Excel before being imported into a statistics tool where Tukey's (1977) exploratory data analysis was used as a guide to graphically represent and understand the data in the context of the study objective. The individual variables were then analysed and compared against one another, specifically considering highs and lows, distribution and proportion as per Sparrow's (1989) guidelines before final hypothesis analysis was completed.

Microsoft Excel produced a set of easy-to-understand tables and graphs on the respondents' demographic profiles after initial data clean-up and formatting was completed. The spreadsheet was then imported into Dell Statistica, where a range of data analysis activities were performed. Initial data analysis focused on descriptive statistics, looking to confirm that the data fell within the available range of each question. In addition to calculating mean and standard deviation data sets for each question, a box and whisker plot was created to give a pictorial representation of the data, with the specific intention of checking the highs and lows of each question to ensure they fell within the available range (Saunders, Lewis \& Thornhill 2009).

Once the data integrity had been validated with the box and whisker plot graph, further statistical analysis was performed to test for reliability. Reliability is a measurement of internal consistency (Trivedi \& Kumar 2014). Cronbach's alpha test was deployed to calculate the internal consistency of the questionnaire's main constructs. Cronbach's alpha test is frequently seen deployed in the literature to evaluate the internal consistency of research instruments. The Cronbach's alpha test outputs a value of internal consistency for each construct, with a threshold level of 0.7 or greater used to determine whether that particular construct has good internal consistency. In this study, except for content delivery, which showed a questionable internal consistency at 0.623 (see Table 2), all other constructs were greater than 0.7 , confirming that the items measured within each of those questions were reliable.
TABLE 2: Cronbach's alpha test.

\begin{tabular}{|c|c|c|c|c|}
\hline Construct & $\begin{array}{l}\text { Number of } \\
\text { items } \\
\text { (questions) }\end{array}$ & Mean & $\begin{array}{l}\text { Standard } \\
\text { deviation }\end{array}$ & $\begin{array}{l}\text { Cronbach's } \\
\text { alpha }\end{array}$ \\
\hline Content delivery & 5 & 20.09 & 2.96 & 0.623 \\
\hline Transactions & 4 & 9.86 & 4.01 & 0.765 \\
\hline $\begin{array}{l}\text { Location-based } \\
\text { services }\end{array}$ & 4 & 14.38 & 5.21 & 0.879 \\
\hline Entertainment & 3 & 8.39 & 3.26 & 0.734 \\
\hline $\begin{array}{l}\text { Perceived ease } \\
\text { of use }\end{array}$ & 4 & 16.25 & 2.45 & 0.919 \\
\hline $\begin{array}{l}\text { Perceived } \\
\text { usefulness }\end{array}$ & 6 & 20.09 & 3.93 & 0.789 \\
\hline $\begin{array}{l}\text { Perceived } \\
\text { enjoyment }\end{array}$ & 4 & 14.32 & 3.02 & 0.926 \\
\hline
\end{tabular}

Subsequent data analysis produced a correlation coefficient, which sought to assess the strength of the relationship between the questionnaire's main constructs. A regression analysis was also performed on each of the study's hypotheses to calculate the probability of the results having occurred by chance.

\section{Findings Respondent profiles}

In total, 88 responses were collected. Seven of these were incomplete and removed from the sample data, leaving 81 responses for statistical analysis. The respondents showed a higher proportion of females at $63 \%$, a bias towards younger participants with $91 \%$ reporting to either be in their 20 s or 30 s and a highly educated base with $75 \%$ reporting to have an undergraduate degree or higher. No responses were captured from those younger than 20, and a limited number of responses were received from those over 40 . The profiles captured might not be representative of the m-commerce user base in South Africa and could be a limiting factor in the reach that this study's findings will have. This has been called out in the limitations section of this paper with some recommendations for possible future studies.

\section{Correlation matrix}

A correlation analysis was conducted as shown in Table 3 (significant correlations of $p<0.05$ ). The findings show a negative correlation between age and m-commerce usage activities in terms of content delivery $(r=-0.132)$, transactions $(r=-0.239)$, location-based services $(r=-0.192)$ and entertainment $(r=-0.113)$. These findings suggest that the younger participants in the study are more likely to engage in using m-commerce activities than older participants. Education produced mostly positive (albeit very weak) correlations to $\mathrm{m}$-commerce usage activities, suggesting that better educated respondents are more likely to engage with m-commerce for content delivery $(r=0.124)$, transactions $(r=0.244)$, location-based services $(r=0.269)$ and entertainment $(r=0.143)$.

Gender indicated some very weak positive correlations to $\mathrm{m}$-commerce usage in terms of content delivery $(r=0.132)$, transactions $(r=0.088)$ and location-based services $(r=0.091)$, whilst entertainment showed a negative correlation to gender 
TABLE 3: Correlation analysis

\begin{tabular}{|c|c|c|c|c|c|c|c|c|c|c|}
\hline Variable & C & $\mathbf{T}$ & LBS & $\mathbf{E}$ & EOU & $\mathbf{U}$ & En & G & A & Edu \\
\hline Content & 1 & - & - & - & - & - & - & - & - & - \\
\hline Transaction & 0.434 & 1 & - & - & - & - & - & - & - & - \\
\hline $\begin{array}{l}\text { Location-based } \\
\text { service }\end{array}$ & 0.467 & 0.417 & 1 & - & - & - & - & - & - & - \\
\hline Entertainment & 0.239 & 0.314 & 0.351 & 1 & - & - & - & - & - & - \\
\hline Ease of use & 0.321 & 0.291 & 0.255 & 0.131 & 1 & - & - & - & - & - \\
\hline Usefulness & 0.385 & 0.474 & 0.282 & 0.154 & 0.318 & 1 & - & - & - & - \\
\hline Enjoyment & 0.49 & 0.332 & 0.335 & 0.114 & 0.341 & 0.651 & 1 & - & - & - \\
\hline Gender & 0.132 & 0.088 & 0.091 & -0.219 & 0.101 & 0.086 & 0.151 & 1 & - & - \\
\hline Age & -0.132 & -0.239 & -0.192 & -0.113 & -0.294 & -0.011 & 0.148 & -0.164 & 1 & - \\
\hline Education & 0.124 & 0.244 & 0.269 & 0.143 & 0.12 & 0.088 & -0.053 & 0.118 & -0.195 & 1 \\
\hline
\end{tabular}

C, content; T, transaction; LBS, location-based service; E, entertainment; EOU, ease of use; U, usefulness; En, enjoyment; G, gender; $A$, age; Edu, education.

TABLE 4: Regression analysis.

\begin{tabular}{lcccc}
\hline Hypothesis & Content & Transactions & Location & Entertainment \\
\hline H1: Age & $p=0.241$ & $p=0.031$ & $p=0.085$ & $p=0.313$ \\
& $r=0.131$ & $r=0.238$ & $r=0.192$ & $r=0.113$ \\
H2: Education & $p=0.270$ & $p=0.028$ & $p=0.015$ & $p=0.201$ \\
& $r=0.123$ & $r=0.243$ & $r=0.269$ & $r=0.143$ \\
H3: Gender & $p=0.240$ & $p=0.435$ & $p=0.420$ & $p=0.049$ \\
& $r=0.131$ & $r=0.087$ & $r=0.090$ & $r=0.218$ \\
H4: Perceived & $p=0.000$ & $p=0.002$ & $p=0.002$ & $p=0.310$ \\
enjoyment & $r=0.489$ & $r=0.331$ & $r=0.335$ & $r=0.114$ \\
H5: Perceived & $p=0.003$ & $p=0.008$ & $p=0.020$ & $p=0.244$ \\
ease of use & $r=0.320$ & $r=0.291$ & $r=0.255$ & $r=0.130$ \\
H6: Perceived & $p=0.000$ & $p=0.000$ & $p=0.010$ & $p=0.169$ \\
usefulness & $r=0.384$ & $r=0.474$ & $r=0.282$ & $r=0.154$ \\
\hline
\end{tabular}

H, Hypothesis

$(r=-0.219)$. Males in this study showed more of an inclination to use m-commerce for entertainment purposes than females, particularly for streaming music. All of the motivational factors (perceived usefulness, perceived ease of use and perceived enjoyment) showed a positive correlation to the different $\mathrm{m}$-commerce usage activities (content delivery, transaction, location-based services and entertainment). This shows that motivation factors play an important role in the respondents engaging in $\mathrm{m}$-commerce.

\section{Regression analysis}

Regression analysis was deployed during hypothesis testing (as shown in Table 4). The tests were carried out with the aim of exploring if the relationships identified from data analysis were significant. A relationship is deemed significant when $p<0.05$ (Saunders et al. 2009). Each of the six hypotheses was evaluated against the four constructs of m-commerce usage, namely content delivery, transactions, location-based services and entertainment. The results show us that there is no significant relationship (i.e. $p<0.05$ ) between age and $\mathrm{m}$-commerce usage activities in terms of content delivery $(p=0.241)$, location-based services $(p=0.085)$ and entertainment $(p=0.313)$. There is a significant relationship between age and transactions ( $p=0.031)$; however, the data show that age is positively related $(r=0.238)$ to $\mathrm{m}$-commerce usage in terms of transactions.

There was no significant relationship (i.e. $p=0.05$ ) between education level and content delivery and entertainment $(p=0.201)$. By contrast, the results show a positive and significant relationship between education level and transactions and location-based services.

Apart from entertainment, no significant relationship was found between gender and content delivery $(p=0.240)$, transactions $(p=0.435)$, and location-based services. However, gender showed a significant and positive relationship towards entertainment. Perceived enjoyment has significant and positive relationships to $\mathrm{m}$-commerce usage in terms of content delivery, transactions and locationbased services. The results show no significant relationship between enjoyment and entertainment. The results showed a significant and positive relationship between perceived ease of use and content delivery, transactions, and location-based services. No significant relationship was found between perceived ease of use and entertainment. Perceived usefulness showed significant and positive relationships with content delivery, transactions and location-based services, but the results were not significant for entertainment where $p=0.169$.

\section{Discussion}

The findings of this study show that there is no significant relationship between age and $\mathrm{m}$-commerce usage activities in terms of content delivery, location-based services and entertainment. This is because young, affluent and single individuals (especially women) tend to be the most positive towards m-commerce adoption (Okazaki 2006). However, our findings suggest that older m-commerce users conduct more transaction-based activities than their younger counterparts. This is not surprising because according to Sorce, Perotti and Widrick (2005) older consumers were more likely to purchase items online once they had searched for the item. Findings also show that $\mathrm{m}$-commerce users, regardless of their education level, engage in content delivery such as news and email as well as entertainment such as online gaming and streaming music and videos online through their mobile devices. A positive and significant relationship between education level and transactions and location-based services was evident in this study, despite this being contrary to Okazaki (2006), who found that well-educated professionals, who are also more mature, tend to be the least positive about m-commerce. Our findings can be explained by linking education level to income and/or purchasing power, whereby those with a higher education could possibly 
have a higher income and purchasing power and are therefore able to conduct more transactions than those with a lower education level. These findings and possible explanations are supported by Bornman (2012), who found that in Africa education and income are positively correlated, and those with a higher level of education will use the Internet more than those with a lower level of education. Similar results are reported by Akhter (2012), who found that income has a significant effect on online spending. More highly educated users might also be able to make better use of, and act on, location-based services such as time-sensitive offers and notifications, leading them to use these services more. The findings, therefore, suggest that most of the m-commerce activities were perceived in the same manner by all age groups, but this perception differed when it came to making transactions that involved substantial monetary exchange.

With the exception of entertainment, no significant relationship was found between gender and content delivery, transactions and location-based services. These results deviate from the popular view in literature that males tend to be more engaged with technology services than females because females prefer the interpersonal communication style gained from going to physical shops, whereas males prefer the utility of online shopping and its related activities. The results, however, confirm those of Chong (2013a). Our findings, contrarily, show a significant and positive relationship between gender and entertainment, with males engaging more in m-commerce entertainment activities such as listening to music and playing games online through their mobile devices. These findings confirm previous studies such as those of Ko et al. (2005), who found that subjects who had previously played online games were predominantly male, although this trend could change in the future given that 'female participation in games continues to grow, and recent statistics indicate that women were $46 \%$ of the most frequent purchasers of video games in 2013' (Veltri et al. 2014:9). Nevertheless, gaming remains the most popular form of entertainment among males and Ko et al. (2005) go to caution us against this trend because 'older age, lower self-esteem, and lower satisfaction with daily life were associated with more severe addiction among males, but not among females'.

Our findings showed a significant relationship between the motivational variables of perceived enjoyment, perceived ease of use and perceived usefulness, and $\mathrm{m}$-commerce usage activities of content delivery, transactions, and locationbased services. Whilst it may seem trivial to explain that users will engage more with m-commerce activities if they find them easy to use, enjoyable or useful, none of these characteristics have a significant relationship with $\mathrm{m}$-commerce entertainment activities. These findings suggest that users will engage in online entertainment activities regardless of the activity's ease of use, usefulness to them or its enjoyment value, which could possibly be an indication that the usage is driven by other motivating social influences such as social interaction and communication via the online gaming platform.

\section{Conclusion}

The purpose of this study was to examine the role of demographic and motivational factors on $\mathrm{m}$-commerce usage activities. Following a positivist stance and an online survey as a data collection technique, the results show that age has no significant relationship with three of the m-commerce usage activities - content delivery, location-based services and entertainment-but is significantly related to $\mathrm{m}$-commerce transactions. The implication is that the age of the users has an effect on their purchasing behaviour. This is contrary to Chong (2013a), who finds that younger users are more likely to use m-commerce for all activities when compared to older users. Our findings can be interpreted that older users are more likely to receive an income, which can influence their transactional decisions, and in Africa in particular income has been found to be the main explanatory variable for usage (Chabossou et al. 2008).

The results also show that one's education status influences the following $\mathrm{m}$-commerce usage activities: transactions and location-based services. One's gender influences how one uses m-commerce, with males being the majority users of entertainment services of $\mathrm{m}$-commerce. Finally, the results show a significant relationship between all three motivational variables (perceived enjoyment, perceived ease of use and perceived usefulness) and m-commerce usage activities of content delivery, transactions and location-based services but no significant relationship with $\mathrm{m}$-commerce entertainment activities.

From a practitioner's point of view, the findings provide the financial services industry with a better understanding of the relationships between customer demographics and the m-commerce activities they engage in, to better customise their product offering. Although the study provides practical contribution and a better explanation of $\mathrm{m}$-commerce activities in South Africa, we are cognisant of several limitations. Firstly, the sample size was small and may therefore not be representative of the entire South African population. Secondly, variables such as income and employment were not included in the research model, which in retrospect appear to be significant factors in interpreting the findings in the context of the study. These concerns will be addressed in the future work of this study.

\section{Acknowledgements Competing interests}

The authors declare that they have no financial or personal relationships which may have inappropriately influenced them in writing this article.

\section{Author's contributions}

M.C. was responsible for conceptual design, data collection and analysis, whilst S.K.K. was responsible for theoretical contribution, presentation of the findings and discussion. 


\section{References}

Akhter, S.H., 2012, 'Who spends more online? The influence of time, usage variety, and privacy concern on online spending', Journal of Retailing and Consumer Services 19(1), 109-115. https://doi.org/10.1016/j.jretconser.2011.10.002

Ayeh, J.K., Au, N. \& Law, R., 2013, 'Predicting the intention to use consumer-generated media for travel planning', Tourism Management 35, 132-143. https://doi. org/10.1016/j.tourman.2012.06.010

Beger, G., Sinha, A. \& Pawelczyk, K., 2012, South African mobile generation. Study on South African young people on mobiles, UNICEF, New York.

Bhatti, T., 2015, 'Exploring factors influencing the adoption of mobile commerce', The Journal of Internet Banking and Commerce 12(3), 32-42.

Bornman, E., 2012, 'The mobile phone in Africa: Has it become a highway to the information society or not', Contemporary Educational Technology 3(4), 278-292.

Budree, A. \& Williams, K.H., 2013, 'Factors influencing the uptake of mobile banking in developing countries: A case study of M - Pesa in South Africa', in Proceedings of 22nd International Business Research Conference, Madrid, Spain, Septembe 9-10, 2013, n.p.

Chabossou, A., Stork, C., Stork, M. \& Zahonogo, P., 2008, 'Mobile telephony access and usage in Africa', The African Journal of Information and Communication 9 , 17-41.

Chetty, M., Sundaresan, S., Muckaden, S., Feamster, N. \& Calandro, E., 2013 'Measuring broadband performance in South Africa', in Proceedings of the 4th
Annual Symposium on Computing for Development - ACM DEV-4 '13, Cape Town, Annual Symposium on Computing for Development - ACM DEV-4 '13, Cape Town,
South Africa, December 06-07, 2013, pp. 1-10. https://doi.org/10.1145/ 2537052.2537053

Cho, Y.J. \& Perry, J.L., 2012, 'Intrinsic motivation and employee attitudes role of managerial trustworthiness, goal directedness, and extrinsic reward expectancy' Review of Public Personnel Administration 32(4), 382-406. https://doi. org/10.1177/0734371X11421495

Chong, A.Y.L., 2013a, 'Mobile commerce usage activities: The roles of demographic and motivation variables', Technological Forecasting and Social Change 80(7) and motivation variables', Technological Forecasting and Soc

Chong, A.Y.L., 2013b, 'Understanding mobile commerce continuance intentions: An empirical analysis of Chinese consumers', Journal of Computer Information Systems 53(4), 22-30. https://doi.org/10.1080/08874417.2013.11645647

Chung, J.E., Park, N., Wang, H., Fulk, J. \& McLaughlin, M., 2010, 'Age differences in perceptions of online community participation among non-users: An extension of the Technology Acceptance Model', Computers in Human Behavior 26(6), 1674-1684. https://doi.org/10.1016/j.chb.2010.06.016

Davis, F.D., Bagozzi, R.P. \& Warshaw, P.R., 1992, 'Extrinsic and intrinsic motivation to use computers in the workplace1', Journal of Applied Social Psychology 22(14), 1111-1132. https://doi.org/10.1111/j.1559-1816.1992.tb00945.x

Dlodlo, N. \& Mafini, C., 2013, 'The relationship between technology acceptance and frequency of mobile commerce use amongst Generation $Y$ consumers', Acto Commercii 13(1), 1-8. https://doi.org/10.4102/ac.v13i1.176

Donner, J., Marsden, G. \& Gitau, S., 2011, 'Exploring mobile-only Internet use: Results of a training study in urban South Africa', International Journal of Communication 5 , 574-597, viewed July 2016, from http://ijoc.org/ojs/index.php/ijoc/article/ view/750/543

Dysvik, A. \& Kuvaas, B., 2013, 'Intrinsic and extrinsic motivation as predictors of work effort: The moderating role of achievement goals', British Journal of Socia Psychology 52(3), 412-430. https://doi.org/10.1111/j.2044-8309.2011.02090.x

Erasmus, E., Rothmann, S. \& Van Eeden, C., 2015, 'A structural model of technology acceptance', SA Journal of Industrial Psychology 41(1), 1-12. https://doi. acceptance', SA Journal of
org/10.4102/sajip.v41i1.1222

Hasan, B., 2010, 'Exploring gender differences in online shopping attitude', Computer in Human Behavior 26(4), 597-601. https://doi.org/10.1016/j.chb.2009.12.012

Hayden, T. \& Webster, T., 2014, The mobile commerce revolution: Business success in a wireless world, Que Publishing, Indianapolis, IN.

Hew, T.S., Leong, L.Y., Ooi, K.B. \& Chong, A.Y.L., 2016, 'Predicting drivers of mobile entertainment adoption: A two-stage SEM-artificial-neural-network analysis' Journal of Computer Information Systems 56(4), 352-370. https://doi.org/10.1080/ 08874417.2016.1164497

Hwang, Y., 2010, 'The moderating effects of gender on e-commerce systems adoption factors: An empirical investigation', Computers in Human Behavior 26(6), 17531760. https://doi.org/10.1016/j.chb.2010.07.002

Joubert, J. \& Van Belle, J.V., 2013, 'The role of trust and risk in mobile commerce adoption within South Africa', International Journal of Business, Humanities and Technology 3(2), 27-38, viewed February 2017, from http://www.ijbhtnet.com/ journals/Vol_3_No_2_February_2013/3.pdf

Kakihara, M., 2014, 'Grasping a global view of smartphone diffusion: An analysis from a global smartphone study', in 2014 International Conference on Mobile Business, Paper 11, viewed April 2016, from http://aisel.aisnet.org/icmb2014/11

Ko, C.H., Yen, J.Y., Chen, C.C., Chen, S.H. \& Yen, C.F., 2005, 'Gender differences and related factors affecting online gaming addiction among Taiwanese adolescents',
The Journal of Nervous and Mental Disease 193(4), 273-277. https://doi. org/10.1097/01.nmd.0000158373.85150.57

Kreutzer, T., 2009, 'Generation mobile: Online and digital media usage on mobile phones among low-income urban youth in South Africa', Digital Media 30, 1-13, viewed April 2016, from http://tinokreutzer.org/mobile/MobileOnlineMediaSurveyResults-2009.pdf
Lee, M.K., Cheung, C.M. \& Chen, Z., 2005, 'Acceptance of Internet-based learning medium: The role of extrinsic and intrinsic motivation', Information \& Management 42(8), 1095-1104. https://doi.org/10.1016/j.im.2003.10.007

Maduku, D.K., 2013, 'Predicting retail banking customers' attitude towards Internet banking services in South Africa', Southern African Business Review 17(3), 76-100.

Mallenius, S., Rossi, M. \& Tuunainen, V.K., 2007, 'Factors affecting the adoption and use of mobile devices and services by elderly people-results from a pilot study', International Journal of Services Sciences 2(1), 29-52. https://doi.org/ 10.1.1.130.2463

Mobility, 2011, The mobile consumer in South Africa 2011, viewed June 2016, from http://www.worldwideworx.com/wp-content/uploads/2011/02/Exec-SummaryThe-Mobile-Consumer-in-SA-2011.doc

Ngai, E.W.T. \& Gunasekaran, A., 2007, 'A review for mobile commerce research and applications', Decision Support Systems 43(1), 3-15. https://doi.org/10.1016/j. dss.2005.05.003

Ngwenyama, O.K. \& Lee, A.S., 1997, 'Communication richness in electronic mail: Critical social theory and the contextuality of meaning', MIS Quarterly 21(2), 145167. https://doi.org/10.1016/j.dss.2005.05.003

North, D., Johnston, K. \& Ophoff, J., 2014, 'The use of mobile phones by South African University students', Issues in Informing Science and Information 11, 115-138. University students', Issues in Informing Scier
https://doi.org/10.1016/j.tele.2011.11.001

Okazaki, S., 2006, 'What do we know about mobile Internet adopters? A cluster analysis', Information \& Management 43(2), 127-141. https://doi.org/10.1016/j. im.2005.05.001

Padilla-Meléndez, A., Del Aguila-Obra, A.R. \& Garrido-Moreno, A., 2013, 'Perceived playfulness, gender differences and technology acceptance model in a blended learning scenario', Computers and Education 63, 306-317. https://doi. org/10.1016/j.compedu.2012.12.014

Pagani, M., 2004, 'Determinants of adoption of third generation mobile multimedia services', Journal of Interactive Marketing 18(3), 46-59. https://doi.org/10.1002/ dir.20011

Phuangthong, D. \& Malisawan, S., 2005, 'A study of behavioral Intention for 3 G mobile Internet technology: Preliminary research on mobile learning', In Special Issue of the International Journal of the Computer, the Internet and Management 13, 1-7.

Ramayah, T. \& Ignatius, J., 2005, 'Impact of perceived usefulness, perceived ease of use and perceived enjoyment on intention to shop online', ICFAI Journal of Systems Management (IJSM) 3(3), 36-51.

Saunders, M., Lewis, P. \& Thornhill, A., 2009, Research methods for business students, 5th edn., Pearson Education Limited, Harlow.

Selyer, C. \& Mugova, C., 2017, 'An investigation into the impact of e-commerce, m-commerce and modern technology on the translation industry in South Africa', Journal of Management \& Administration 2017(1), 1-23.

Shava, H., Chinyamurindi, W. \& Somdyala, A., 2016, 'An investigation into the usage of mobile phones among technical and vocational educational and training students in South Africa', South African Journal of Information Management 18(1), 1-8. https://doi.org/10.4102/sajim.v18i1.716

Sorce, P., Perotti, V. \& Widrick, S., 2005, 'Attitude and age differences in online buying', International Journal of Retail \& Distribution Management 33(2), 122-132. https://doi.org/10.1108/09590550510581458

Sparrow, J.A., 1989, 'Graphical displays in information systems: Some data properties influencing the effectiveness of alternative forms', Behaviour \& Information Technology 8(1), 43-56. https://doi.org/10.1080/01449298908914537

Stork, C., Calandro, E. \& Gillwald, A., 2013, 'Internet going mobile: Internet access and use in 11 African countries', Info 15(5), 34-51. https://doi.org/10.1108/info-052013-0026

Tecnológica, B., Países, E.N.L.O.S., Desarrollo, E.N. \& Experiencia, L.A., 2015 'Consumers' readiness to accept technology-based products and services in developing countries: The Chilean experience', Multidisciplinary Business Review developing $14-24$.

Teo, T.S.H., 2001, 'Demographic and motivation variables associated with Internet usage activities', Internet Research 11(2), 125-137. https://doi.org/10.1108/106 usage activities',
62240110695089

Touray, A., Salminen, A. \& Mursu, A., 2013, 'ICT barriers and critical success factors in developing countries', The Electronic Journal of Information Systems in Developing Countries 56, 1-17. https://doi.org/10.1002/j.1681-4835.2013.tb00401.x

Trivedi, J.P. \& Kumar, S., 2014, 'Determinants of mobile commerce acceptance amongst gen $Y^{\prime}$, Journal of Marketing Management 2(2), 145-163.

Tukey, J.W., 1977, Exploratory data analysis, 1st edn, Addison-Wesley, Reading, PA.

Veltri, N., Krasnova, H., Baumann, A. \& Kalayamthanam, N., 2014, 'Gender differences in online gaming: A literature review', In 2014 Americas Conference on Information Systems, Savannah, GA, viewed June 2016, from http://citeseerx.ist.psu.edu/ viewdoc/download?doi=10.1.1.667.4530\&rep=rep1\&type=pdf

Walsham, G., 1995, 'Interpretive case studies in IS research: Nature and method', European Journal of Information Systems 4(2), 74-81. https://doi.org/10.1057/ ejis.1995.9

Wentzel, J.P., Diatha, K.S. \& Yadavalli, V., 2013, 'An application of the extended Technology Acceptance Model in understanding technology-enabled financial service adoption in South Africa', Development Southern Africa 30(4-5), 659-673. service adoption in South Africa, Development So
https://doi.org/10.1080/0376835X.2013.830963

Wu, J.H. \& Wang, S.C., 2005, 'What drives mobile commerce? An empirical evaluation of the revised technology acceptance model', Information and Management 42(5), 719-729. https://doi.org/10.1016/j.im.2004.07.001 